\title{
Impact of LOD Score and Recombination Frequencies on the Microsatellite Marker Based Linkage Map for Drought Tolerance in Kharif Rice of Assam
}

\author{
Jyoti Prakash Sahoo $^{1 *}$ and Vinay Sharma ${ }^{2}$ \\ ${ }^{1}$ Department of Agricultural Biotechnology, OUAT, Bhubaneswar, India \\ ${ }^{2}$ Department of Agricultural Biotechnology, AAU, Jorhat, India \\ *Corresponding author
}

\section{A B S T R A C T}

\section{Keywords \\ Drought, Join Map 4.0, LOD Score, Mapping \\ Population, SCL Values, SSR \\ Article Info \\ Accepted: \\ 20 July 2018 \\ Available Online: \\ 10 August 2018}

\begin{abstract}
Intermittent drought stress in rainfed ecosystem significantly limits the production of Ranjit, the most predominant high yielding rice variety of North East India. In order to understand the genetic basis of drought tolerance a mapping population comprising $85 \mathrm{~F}_{4}$ individuals between 'Ranjit' and a drought tolerant cultivar, ARC10372 was developed and genotyped with 80 microsatellite markers. 7 possible linkage groups were analysed by changing the LOD values and the recombination frequencies in the Join map 4.0 software package. Only 3 linkage groups were considered out of the 7 linkage groups as the map was calculated at LOD threshold 3.0 and above. It could be concluded that, higher critical LOD values will result in more number of fragmented linkage groups, each with smaller number of markers while small LOD values will tend to create few linkage groups with large number of markers per group.
\end{abstract}

\section{Introduction}

Rice is one of the most widely grown cereal crops in the world and is the staple food of more of the world's population (Chen et al., 2013). In 2008, a total of 661 million tons of rice was produced from 155.7 million ha (IRRI, 2009). Rice is cultivated in a wide range of environments such as irrigated, rainfed upland, rainfed lowland, flooded and saline, and it faces multiple biotic and abiotic challenges. According to the USDA reports, in 2008, more than 430 million metric tons of rice was consumed worldwide and about 3.5 billion people depend on rice for more than 20 per cent of their daily calories. It is estimated that the demand for rice will be 2,000 million metric tons by 2030 due to population increment (FAO, 2002) and according to another report, production of rice must increase by 60 per cent by the end of 2025 (Chen et al., 2013).

Drought mitigation in rice production to ensure food security to the rising population in Asia can be achieved through development of drought-tolerant rice varieties with higher yields. In Asia, drought stress is a major threat to both rainfed lowland (46 Mha) and upland (10 Mha) rice production, affecting the yield stability (Pandey et al., 2007). In Assam, total cultivated area is approx. 30 lakh hectares. Among them 23.24 lakh hectares of land is under paddy cultivation and usually most of 
them are affected by intermittent drought (Directorate of Economics and Statistics, Government of Assam). Ranjit is the leading variety of Assam which is a drought susceptible high yielding variety. ARC 10372 is a drought tolerant moderately yielding variety which matures earlier than the Ranjit. Linkage analysis in a mapping population derived from cross between Ranjit and ARC 10372 will help us to identify the genes contributing to drought tolerance in rice and their relative contribution to the very important trait.

\section{Materials and Methods}

\section{Plant Materials}

The mapping population comprised $85 \mathrm{~F}_{4}$ lines derived from a cross between Ranjit $\times$ ARC10372. ARC10372 was used as a drought tolerant parent and a widely cultivated HY rice variety of North East India, Ranjit was used as the susceptible parent. The parents were crossed to raise $F_{1} s$. True $F_{1} s$ were identified using polymorphic SSR marker and selfed to raise the $F_{2}$ plants. The $F_{2}$ plants were harvested and bulked to raise $F_{3}$ population. Seeds of $85 \mathrm{~F}_{3}$ lines were developed in this way and the population was advanced to $F_{4}$ generation which has been ultimately used as mapping population in this study.

\section{Genotyping and construction of genetic linkage Map}

Plant genomic DNA was extracted from young leaf tissue for each of the $85 \mathrm{~F}_{4}$ lines along with parents, as described in Gupta et al., 2003. The quality of DNA extracted was checked by electrophoreting the samples using 0.8 percent agarose gel and quantified using Nanodrop® ND-1000 Spectrophotometer. Polymerase chain reactions for SSR analysis were carried out under standard conditions for all the primer pairs using $1 \mathrm{U}$ of Taq polymerase with $1 \mathrm{X}$ polymerase chain reaction buffer $(100 \mathrm{mM}$ Tris- $\mathrm{HCl}$ at $\mathrm{pH} \mathrm{9}$, $500 \mathrm{mM} \mathrm{KCl}$, and $15 \mathrm{mM} \mathrm{MgCl} 2$ ), 2.5mMdNTP, $3 \mathrm{mM} \mathrm{MgCl}_{2}, 20 \mathrm{pM}$ of each primer, and $50 \mathrm{ng}$ of DNA template with a final reaction volume of $10 \mu \mathrm{L}$. The PCR reactions were denatured at $94^{\circ} \mathrm{C}$ for 5 minutes followed by 35 cycles of $94^{\circ} \mathrm{C}$ for 1 minute, $55^{\circ} \mathrm{C}$ for 1 minute and $72^{\circ} \mathrm{C}$ for 1 minute.

The final extension was $72^{\circ} \mathrm{C}$ for 5 minutes. The amplified products were resolved in 3.5 percent agarose gel stained with ethidium bromide. The polymorphic SSR markers reported by Verma et al., 2017 were used for genotyping of $85 \mathrm{~F}_{4}$ plants in order to study the segregation pattern of markers.

\section{Statistical analysis}

The PCR fragments were scored for presence and absence. Spurious and missing data were repeated for verification. Chi-square test was conducted to compute the segregation pattern of each SSR marker against the expected ratio in $\mathrm{F}_{4}$ generation at 0.01 probability level. Linkage analysis was performed by using JoinMap 4.0 (Stam et al., 1993) software. Markers were assigned to linkage groups using the odds ratios and grouping was done by considering the SCL (Strongest cross link) values. 7 possible linkage groups were observed (Table 1).

The linkage parameters like weak linkages with a recombination frequency larger than 0.45 or a LOD smaller than 0.05 or strong linkages with a recombination frequency smaller than 0.01 or a LOD larger than 10 were set in the calculation options along with regression mapping algorithm of the software programme. Kosambi's mapping function was selected and the LOD scores were changed from 1.00 to 8.00 to calculate the map distance. 


\section{Results and Discussion}

Increase in LOD threshold may decrease the possibility of linkage group establishment. But sufficient linkage was observed in the linkage groups 2, 3, 4, 6 and 7 to get the map distance at recombination frequency $0.40,0.30$ and 0.20. But Group 4, 6 and 7 were only considered as the map was calculated at LOD threshold 3.0 and above (Fig. 1). The markers RM72, RM335 and RM25 were put to the linkage group 2 of $35.6 \mathrm{mb}$ length at LOD threshold 1.0 and 2.0. As per earlier work, RM25 was mapped on chromosome number 8 at a distance $38.1 \mathrm{mb}$ (Cho et al., 1998) and RM72 was mapped on chromosome number 8 at a distance $30.5 \mathrm{mb}$ (www.gramene.org) and our results are in agreement with these results. However, the marker RM335 has been mapped on chromosome number 4 at a distance $5.4 \mathrm{mb}$ (www.gramene.org), which is in the linkage group with markers from chromosome number 8 in the present study. The map was calculated at LOD threshold 1.0 and 2.0, due to which RM335 came to this group due to low stringency. This can also be explained if there has been any chromosomal translocation in the population under study. This need to be verified by detailed wet-lab experimentations. Similarly, in linkage group 3, markers RM209, RM202 and RM167 were assigned to the map at $0,28.7$ and $51.9 \mathrm{mb}$ respectively at LOD threshold 1.0. As per earlier work, all the markers RM209, RM167 and RM202 were mapped in chromosome 11 (Septiningsih et al., 2003; Xiao et al., 1998). As such, the results of the present study are more or less in agreement with earlier results. In linkage group 4, the marker RM336 and RM1132 were fall apart in $25.2 \mathrm{mb}$ from each other and the other marker RM182 was assigned at $55.6 \mathrm{mb}$ respectively. As per earlier work, RM336 was mapped in chromosome 7 at a distance 55.7, RM182 was mapped in chromosome 7 at a distance 54.8 mb (IRGSP, 2005) and RM1132 was mapped in chromosome 7 at a distance $23.9 \mathrm{mb}$ (Gramene Annotated Nipponbare Sequence, 2009). In group 6, the marker RM19629 and RM253 were placed in a distance of $19.6 \mathrm{mb}$ and RM253 was mapped in chromosome 6 at a distance $20.4 \mathrm{mb}$ (Xiao et al., 1998). As such, the results of the present study are in agreement with earlier results.

Fig.1 Linkage groups according to LOD scores with ARC10372× Ranjit-F 4 population (Left side of bar represents position of marker in $\mathrm{mb}$ and right side of bar represents SSR markers)

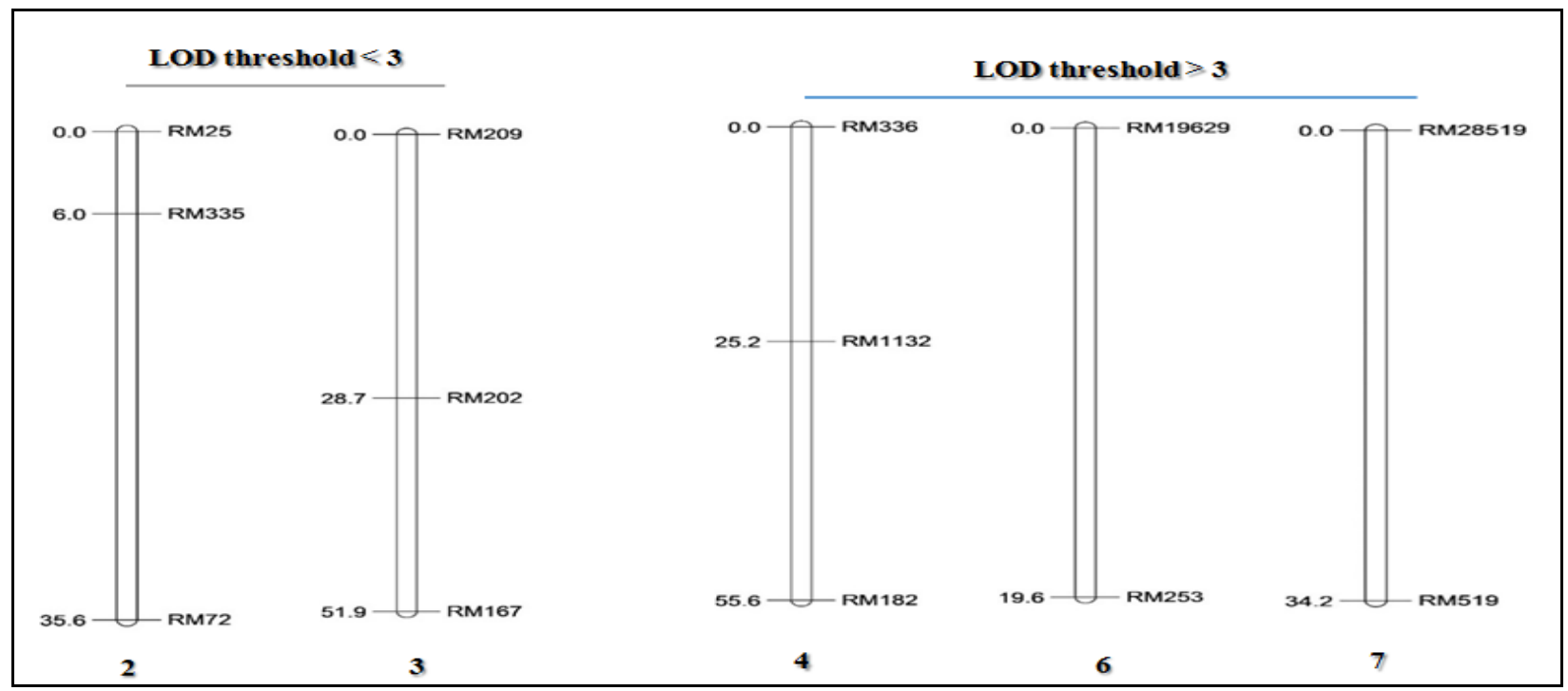


Table.1 Grouping based on LOD score showing SCL values

\begin{tabular}{|l|l|l|l|c|l|l|c|}
\hline Nr & Group & Locus & Node & SCL-Nr & SCL-Locus & SCL-Node & SCL Value \\
\hline 3 & 1 & RM24 & $4.0 / 1(4)$ & 4 & RM243 & $4.0 / 51(1)$ & 2.3 \\
\hline 25 & 1 & RM273 & $4.0 / 1(4)$ & 4 & RM243 & $4.0 / 51(1)$ & 1.6 \\
\hline 7 & 1 & RM5638 & $4.0 / 1(4)$ & 4 & RM243 & $4.0 / 51(1)$ & 3.0 \\
\hline 49 & 2 & RM25 & $4.0 / 2(3)$ & 47 & RM429 & $4.0 / 36(1)$ & 1.9 \\
\hline 28 & 2 & RM335 & $4.0 / 2(3)$ & 39 & RM253 & $4.0 / 6(2)$ & 1.3 \\
\hline 51 & 2 & RM72 & $4.0 / 2(3)$ & 15 & RM530 & $4.0 / 14(1)$ & 1.3 \\
\hline 70 & 3 & RM167 & $4.0 / 3(3)$ & 72 & RM206 & $4.0 / 31(1)$ & 2.2 \\
\hline 71 & 3 & RM202 & $4.0 / 3(3)$ & 43 & RM125 & $4.0 / 34(1)$ & 2.6 \\
\hline 73 & 3 & RM209 & $4.0 / 3(3)$ & 4 & RM243 & $4.0 / 51(1)$ & 1.8 \\
\hline 48 & 4 & RM1132 & $4.0 / 4(3)$ & 70 & RM167 & $4.0 / 3(3)$ & 1.8 \\
\hline 45 & 4 & RM182 & $4.0 / 4(3)$ & 24 & RM261 & $4.0 / 23(1)$ & 1.2 \\
\hline 46 & 4 & RM336 & $4.0 / 4(3)$ & 30 & RM164 & $4.0 / 27(1)$ & 1.3 \\
\hline 35 & 5 & RM141 & $4.0 / 5(3)$ & 72 & RM206 & $4.0 / 31(1)$ & 2.1 \\
\hline 31 & 5 & RM169 & $4.0 / 5(3)$ & 18 & RM1256 & $4.0 / 17(1)$ & 3.1 \\
\hline 32 & 5 & RM249 & $4.0 / 5(3)$ & 34 & RM574 & $4.0 / 28(1)$ & 3.9 \\
\hline 42 & 6 & RM19629 & $4.0 / 6(2)$ & 18 & RM1256 & $4.0 / 17(1)$ & 2.5 \\
\hline 39 & 6 & RM253 & $4.0 / 6(2)$ & 19 & RM1352 & $4.0 / 18(1)$ & 2.1 \\
\hline 80 & 7 & RM28519 & $4.0 / 7(2)$ & 76 & RM235 & $4.0 / 13(1)$ & 3.1 \\
\hline 78 & 7 & RM519 & $4.0 / 7(2)$ & 53 & RM256 & $4.0 / 38(1)$ & 2.8 \\
\hline & & & & & & \\
\hline
\end{tabular}

In group 7, the markers (RM28519 and RM519) were placed in $34.2 \mathrm{mb}$ of length from each other in the map. As per earlier reports, both markers (RM28519 and RM519) were mapped in chromosome 12 at a distance $19 \mathrm{mb}$ and $23 \mathrm{mb}$ respectively (Gramene Annotated Nipponbare Sequence, 2009). So, the present genetic map of rice can be used further for introgression of various QTLs identified under drought stress. To construct a saturated linkage map, more number of markers are required.

As less number of markers were found polymorphic in the $F_{4}$ mapping population, the length of the linkage map as well as the interval size between the markers were reduced. Genetic maps with good genome coverage and confidence in locus order requires not only large numbers of DNA markers, but also the analysis of large numbers of individuals.

\section{Acknowledgements}

The authors gratefully acknowledge the DBTAAU Centre and Dr. T. Ahmed, Chief Scientist, RARS, Titabar for providing the logistic support to the lab work and field work.

\section{References}

Chen M, Presting G, Barbazuk WB, Goicoechea JL, Blackmon B, FangG, et al., (2002). An integrated physical and genetic map of the rice genome. Plant Cell 14: 537-545.

Cho YG, Ishii $\mathrm{T}$, Temmykh $\mathrm{S}$, Chen $\mathrm{X}$, Lipovich L, McCouch SR, Park WD, Ayres N, Cartinhour S (2000). Diversity of microsatellites derived from genomic libraries and gene bank sequences in rice (Oryza sativa L.). Theor. Appl. Genet. 100: 713-722. 
Gupta PK, Rustgi S, Sharma S, Singh R, Kumar N, Balyan HS (2003) Transferable EST-SSR markers for the study of polymorphism and genetic diversity in bread wheat. Mol Genet Genomics 270(4): 315-323

Hackett CA, Broadfoot LB (2003) Effects of genotyping errors, missing values and segregation distortion in molecular marker data on the construction of linkage maps. Heredity 90(1):33-38

Hubert B, Rosegrant M, van Boekel MAJS, Ortiz R (2010). The future of food: scenarios for 2050. Crop Sci 50:S33S50

Irri, I (2002) Standard evaluation system for rice. International Rice Research Institute, Philippine

Kurata, N., Nagamura, Y., Yamamoto, K., Harushima, Y., Sue, N., Wu, J., and Inoue, T. (1994). A 300 kilobase interval genetic map of rice including 883 expressed sequences. Nature genetics, 8(4), 365-372.

McCouch SR, Chen X, Panaud O, Temnykh $\mathrm{S}, \mathrm{Xu}$ Y, Cho Y, Huang N, Ishii T, Blair M (1997) Microsatellite marker development,mapping, and applications in rice genetics and breeding. Plant Mol Biol 35:89-99

McCouch SR, Doerge RW (1995) QTL mapping in rice. Trends Genet 11:482487

McCouch, S.R., X. Chen, O. Panaud, S. Temnykh, Y. Xu, Y. Cho, N. Huang, T. Ishii and M. Blair, 1997. Microsatellite marker development, mapping and applications in rice genetics and breeding. Plant MolBiol 35: 89-99.

N'Diaye, A., Haile, J. K., Fowler, D. B., Ammar, K., and Pozniak, C. J. (2017). Effect of Co-segregating Markers on High-Density Genetic Maps and Prediction of Map Expansion Using Machine Learning Algorithms. Frontiers in Plant Science, 8, 1434.
O' Toole JC, Bland WL (1987). Genotypic variation in crop plant root system. Adv Agron 41: 91-145

Pandey S, Bhandari H: Drought: economic costs and research implications. In Drought frontiers in rice: crop improvement for increased rainfed production. Edited by: Serraj R, Bennett J, Hardy B. World Scientific Publishing, Singapore; 2009: 3-17.

Peng, S. et al., Rice yields decline with higher night temperature from global warming. Proc. Natl Acad. Sci. USA 101, 9971-9975 (2004).

Peng, S., Bouman, B., Visperas, R. M., Castañeda, A., Nie, L., and Park, H. K. (2006). Comparison between aerobic and flooded rice in the tropics: agronomic performance in an eightseason experiment. Field Crops Research, 96(2), 252-259.

Price AH, Courtois B (1999). Mapping QTLs associated with drought resistance in rice: progress, problems and prospects. Plant Growth Regul, 29: 123-133.

Prince, S. J., Beena, R., Gomez, S. M., Senthivel, S., \&Babu, R. C. (2015). Mapping consistent rice (Oryza sativa L.) yield QTLs under drought stress in target rainfed environments. Rice, 8(1), 1.

Quillet MC, Madjidian N, Griveau Y, Serieys $\mathrm{H}$, Tersac M, Lorieux M, Berville A (1995) Mapping genetic factors controlling pollen viability in an interspecific cross in Helianthus sect. Helianthus. Theor Appl Genet 91(8):1195-1202

Risch N (1992). Genetic linkage: Interpreting LOD scores. Science 255:803-804.

Semagn, K., Bjørnstad, Å. and Ndjiondjop, M. N. (2006). Principles, requirements and prospects of genetic mapping in plants. African Journal of Biotechnology, 5(25). 
Septiningsih, E. M., Prasetiyono, J., Lubis, E., Tai, T. H., Tjubaryat, T., Moeljopawiro, S., and McCouch, S. R. (2003). Identification of quantitative trait loci for yield and yield components in an advanced backcross population derived from the Oryza sativa variety IR64 and the wild relative $O$. rufipogon. Theoretical and applied genetics, 107(8), 1419-1432.

Servin B, Hospital F (2002) Optimal positioning of markers to control genetic background in marker-assisted backcrossing. J Hered 93(3): 214-217

Stam P (1993a) Construction of integrated genetic linkage maps by means of a new computer package: JoinMap. Plant J 3: 739-744

Tao YZ, Henzell RG, Jordan DR, Butler DG, Kelly AM, McIntyre CL (2000) Identification of genomic regions associated with stay green in sorghum by testing RILs in multiple environments. Theor Appl Genet 100: 1225-1232

The Arabidopsis Genome Initiative (2000). Analysis of the genome sequence of the flowering plant Arabidopsis thaliana. Nature 408: 796-815.

The Rice Genome Sequencing Project (2005). The map-based sequence of the rice genome. Nature436: 793-800.

Van Ooijen JW, Voorrips RE (2001). Join Map® 3.0, Software for the calculation of genetic linkage maps. Plant Research International, Wageningen, the Netherlands.

Verma RK (2017). Mapping and dissection of genetic effects into QTLs for grain yield

\section{How to cite this article:}

Jyoti Prakash Sahoo and Vinay Sharma. 2018. Impact of LOD Score and Recombination Frequencies on the Microsatellite Marker Based Linkage Map for Drought Tolerance in Kharif Rice of Assam. Int.J.Curr.Microbiol.App.Sci. 7(08): 3299-3304. doi: https://doi.org/10.20546/ijcmas.2018.708.352 under drought in elite rice variety of Assam. PhD Thesis, Assam Agricultural University, Jorhat, India

Verma RK, Chetia SK, Dey PC, Baruah AR, Modi MK (2017) Mapping of QTLs for grain yield and its component traits under drought stress in elite rice variety of Assam. Int J Curr Microbiol App Sci 6: $1443-1455$

Vision TJ, Brown DG, Shmoys DB, Durrett RT, Tanksley SD (2000).Selective mapping: a strategy for optimizing the construction of high density linkage maps. Genetics 155: 407-420.

Xiao, J., Li, J., Grandillo, S., Ahn, S. N., Yuan, L., Tanksley, S. D., and McCouch, S. R. (1998). Identification of trait-improving quantitative trait loci alleles from a wild rice relative, Oryzarufipogon. Genetics, 150(2), 899909.

Youens-Clark, K., Buckler, E., Casstevens, T., Chen, C., DeClerck, G., Derwent, P., and $\mathrm{Lu}, \mathrm{J}$. (2010). Gramene database in 2010: updates and extensions. Nucleic acids research, 39(suppl_1), D1085D1094.Sasaki, T., and Burr, B. (2000). International Rice Genome Sequencing Project: the effort to completely sequence the rice genome. Current opinion in plant biology, 3(2), 138-142.

Zivy M, Devaux P, Blaisonneau J, Jean R, Thiellement H (1992) Segregation distortion and linkage studies in microspore-derived double haploid lines of Hordeum Vulgare L. Theor Appl Genet 83(6): 919-924 